\title{
Design on Competency Index System of Huansu Motor Sales Personnel
}

\author{
Lihong Han \\ College of Economics and Management \\ Hebei University of Science and Technology \\ Shijiazhuang, China \\ 1070225171@qq.com
}

\author{
Yu Zhao \\ College of Economics and Management \\ Hebei University of Science and Technology \\ Shijiazhuang, China \\ 1092017347@qq.com
}

\begin{abstract}
Enterprises should not only be regarded as the combination of products and services, it also should be the combination of capabilities. Sales staff's capacity and quality directly relate to "lifeline" of an enterprise. The paper focuses on the practical sales work of Beijing Automotive Huansu auto in Sichuan province and obtains relevant post competency information of the sales staff through behavioral event interview and questionnaire survey methods. On the basis of fully utilizing McClelland sales competency model, the paper designs sales employees' competency index system through effectively devising interview outline and questionnaire, finishing records and coding, data analysis and finishing steps etc., in order to provide reference value to select outstanding sales staff and predict their performance.
\end{abstract}

Keywords-post competency ; behavioral event interview; interview outline ; competency model; competency index system

\section{INTRODUCTION}

With continuously deepening of market economy, sales become the core of enterprises to realize their own value and corporate mission. To build a high quality, high efficiency and extraordinary work strength sales team is the decisive factor for enterprise to create outstanding sales performance, hence the sales personnel's quality and ability are keys to sales work. On quality characteristics of specific position, Harvard professor David, McClelland puts forward to the concept of competency, which refers to individual characteristics possessed by outstanding performance employees in the specific post, organizational environment and cultural atmosphere, such as knowledge, skills, attitudes, values, personality traits and motive, and those can be deeper level of personal characteristics that can distinguish excellent employees and ordinary employees.

Competency model is the series of various personal qualities for employees to be competent for a certain post. Competency model plays a basic and decisive role in human resource management. It provides a strong foundation for enterprises in doing job analysis, staff recruitment, staff training, performance appraisal and staff career planning etc. Therefore, using the scientific method to determine the necessary ability and quality of sales jobs become the top priority of completing sales work.

\section{BASIC REQUIRMENT OF COMPETENCY MODEL}

First of all, the competency model should represent industry characteristics. Sales personnel competency model reflects sales staff's overall ability and quality requirements in certain type industry, principally including sales staffs' sales performance, communication skills and reaction ability.

Secondly, the competency model should embody enterprises characteristics. Sales personnel competency model is not a universal model, since each enterprise has different corporate culture, business areas and procedure, so the sales personnel's ability quality model should adjust according to the enterprises' actual situation.

Finally, the competency model should possess phase characteristics. Sales personnel competency model predicts the sales behavior of sales staff, while the development strategy of enterprise determines sales staffs' job objective and behavior, as a result, sales personnel competency model should relate to the enterprise goal programming and be regularly adjusted.

\section{CONSTRUCTION OF INDEX SYSTEM}

The paper looks at the sales work reality of Beijing Automotive Huansu auto in Sichuan area. Sichuan marketing area is one of whole 32 areas marketing Huansu auto in China and mainly takes charge of sales management of Huansu auto brand. There are more than 300 front line sales employees in Sichuan district, mainly from the prefecture level city and the ages of 25 to 35 accounts for above $70 \%$ in sales employees' age distribution. Sale staffs are in the golden age of career development and have abundant energy and strong achievement motivation.

Based on comprehensive acquaintance of current sales staffs' position information, the paper summarized the front line sales staffs' job description in Table I. Then the paper attains the key events using behavior event interview (BEI) method in order to withdraw sales staffs' competency quality. 
TABLE I. JOB DESCRIPTION OF HUANSU SALES STAFF

\begin{tabular}{ll}
\hline classification & establish, maintain and expand the terminal sales, complete the prescriptive distribution objective and plan \\
\hline position summary & 1.effective implementation of various kinds of automobile marketing strategy \\
Job description & 2.Complete the sales tasks and targets assigned by the company \\
3. receiving customer, providing high quality car consulting and supporting services & 4.developing and expanding Huansu motor user groups \\
5. complete job diary and manage customer profiles \\
6. participate in company's all kinds of sales related meeting and training
\end{tabular}

\section{A. Compile interview outline}

Interview outline as a collecting information tool to guide the direction of interview is a key part in BEI. The interview outline content mainly includes three aspects: the first part mainly allows interviewees to make selfintroduction; the second part asks participants to talk about some typical sales situation (success or failure) through the way of memory; the third part is the summary and extension.

\section{B. interview sample selection}

On sample selection, the paper chooses three franchisee stores in Sichuan areas as investigation object, those three stores separately located in Dazhou, Neijiang, Panzhihua, which have good representativeness for the three stores car sales ranking in Sichuan region is respectively the second, the eighth and 15th in 2014(Fig.1),

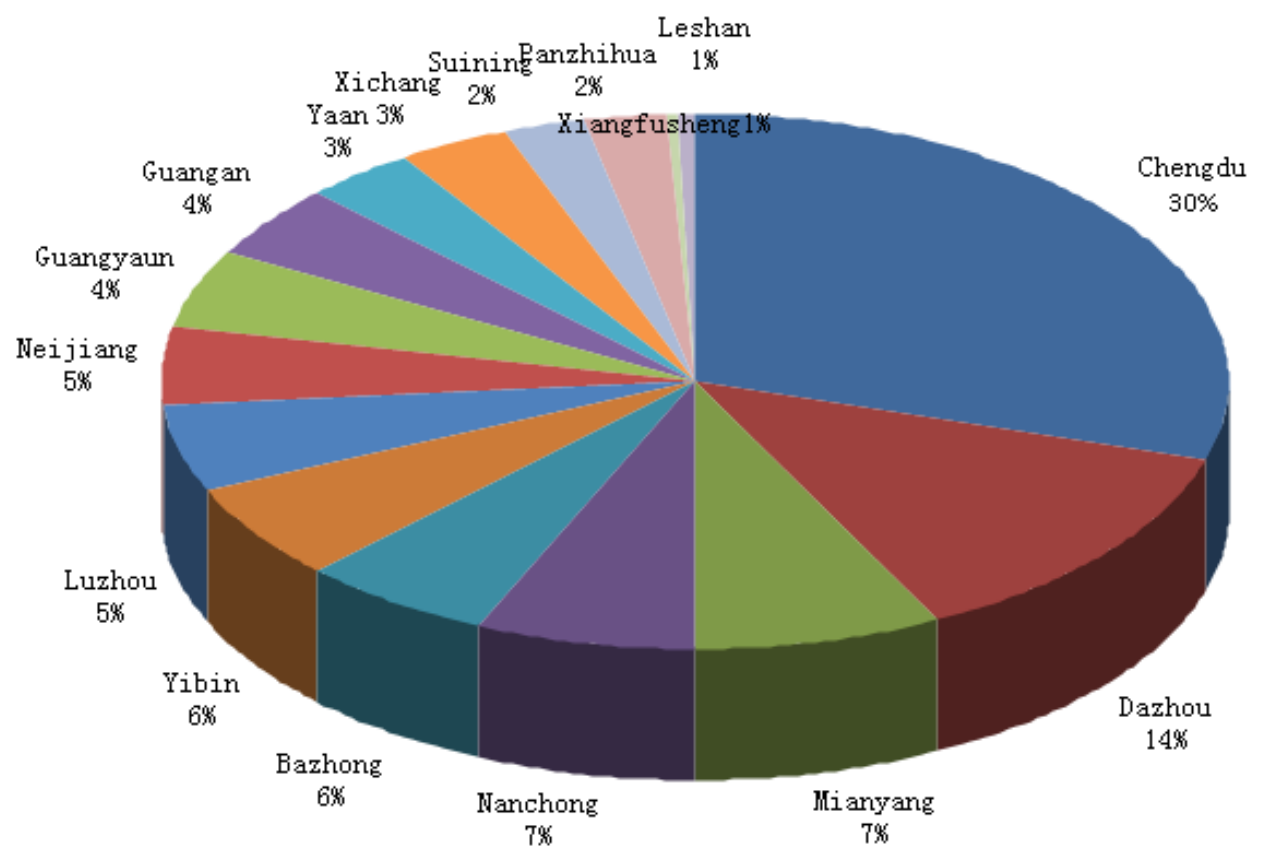

Figure 1. Huansu dealer sales proportion of Sichuan province in 2014

The paper selects two sample groups for depth interviews on the basis of internal performance criteria given by these stores, these two samples are respectively high and common achievement group. On the choice of specific interview objects, high achievement group includes 12 sales employees whose sales performance are the best and also one employee who has just been promoted to deputy manager of the sales department during last year; common group includes 12 sales employees whose sales performance are general and also one employee who has poor sales performance. During the process of sample selection, the author also has a sample snapshot of gender, age, working experience and job information. Average interview time of every sample controls about 30 minutes.

The survey removed two unsuccessful interview samples, so there are totally 24 effective interview samples. C. implement interview process

Interview place is located in the headquarters of Huansu auto in Sichuan. The whole interview process did 
the recording processing by achieving approval of interviewees beforehand. There are five interviewees who cannot be present due to special reasons and be interviewed by means of telephone after discussion. All interviewers utilize participating ways of conversation skills to do the information collection work after systematic training; During the process of detailed conversation with interviewees, interviewers grasp the content and focus of conversation all times to make the $\mathrm{BEI}$ interview process reasonable.

After the interview, interviewers arrange the interview material and transform reduced data into written text. In the end, the paper derived 263 key events from 578 minutes of talk.

\section{Interview coding}

On the basis of effectively sorting interview records, the paper starts coding record. By using McClelland sales competency model, the paper marks the critical behavior and incidents of sales employees during interview and conducts first and secondary coding for the whole interview records by reference to the competency dictionary of related concepts and categories. Demonstration is as follows:

TABLE II. BEI INTER VIEW CODING DEMONSTRATION

I: What do you think is the most successful sales experience in your job?

P: During car sales process, employees must be good at discovering the right

person."...and make efforts to let the customers believe me, our products and our car's

quality。 It's really hard sometimes, especially when customers also have certain

understanding of other brands, they tend to compare the other brand's advantage with

our shortcomings. In order to convince consumers, sometimes we need a lot of skills....
Ability trait

Interpersonal understanding

psychological traits

confidence

Professional skills
Marketing skills

\section{E. construct index system}

From the above interview records, the paper combining McClelland sales competency model encodes and sorts respectively 263 key events, finally produces 24 competency quality items. Through the comparison of outstanding performance group with general performance group in aspects of present frequency and level difference in each competency characteristic, the paper determines the quality items which are obviously different in $\mathrm{T}$ test. Finally according to the results of $\mathrm{T}$ test, the paper summarized competency items which have significant difference in two sets of samples. Test result is as Table III 
TABLE III. COMPETENCY QUALITY ITEM TEST

\begin{tabular}{|c|c|c|c|c|c|}
\hline \multirow[t]{2}{*}{ Compared item } & \multicolumn{2}{|c|}{ High performance group } & \multicolumn{2}{|c|}{ General performance group } & \multirow[t]{2}{*}{ T test } \\
\hline & Average Frequency & $\begin{array}{l}\text { standard } \\
\text { deviation }\end{array}$ & Average Frequency & $\begin{array}{l}\text { standard } \\
\text { deviation }\end{array}$ & \\
\hline Confidence & 0.92 & 0.1946 & 0.24 & 0.0947 & $4.212 * *$ \\
\hline Autonomy & 0.86 & 0.0941 & 0.34 & 0.1042 & $3.023^{* *}$ \\
\hline Tenacity & 0.73 & 0.0972 & 0.42 & 0.1055 & $4.651^{* *}$ \\
\hline Achievement Motivation & 0.57 & 0.0993 & 0.44 & 0.1098 & $2.668^{* *}$ \\
\hline Responsibility & 0.90 & 0.1810 & 0.52 & 0.0945 & $2.687^{* *}$ \\
\hline Product Knowledge & 0.76 & 0.0853 & 0.132 & 0.1055 & $3.454 * *$ \\
\hline Communication Skills & 0.64 & 0.0723 & 0.48 & 0.1063 & 0.455 \\
\hline Innovative Thinking & 0.77 & 0.0834 & 0.37 & 0.1387 & 2.577 \\
\hline Market Analysis & 0.82 & 0.0922 & 0.49 & 0.1053 & $2.677^{* *}$ \\
\hline General Sales Skills & 0.91 & 0.1423 & 0.54 & 0.1241 & $2.578^{* *}$ \\
\hline $\begin{array}{c}\text { Problem Solving } \\
\text { Capabilities }\end{array}$ & 0.87 & 0.0938 & 0.34 & 0.1098 & $3.451^{* *}$ \\
\hline Interpersonal Skills & 0.76 & 0.0892 & 0.53 & 0.0942 & $2.312^{*}$ \\
\hline Strain Capacity & 0.62 & 0.0810 & 0.46 & 0.1364 & $2.431 * *$ \\
\hline Influence & 0.54 & 0.0630 & 0.34 & 0.1223 & 1.432 \\
\hline Team spirit & 0.75 & 0.0827 & 0.63 & 0.1067 & $0.244^{* *}$ \\
\hline Education & 0.66 & 0.0756 & 0.53 & 0.1054 & $1.456^{*}$ \\
\hline Work Experience & 0.61 & 0.0782 & 0.35 & 0.0943 & $1.769^{*}$ \\
\hline Logical Analysis & 0.62 & 0.0792 & 0.46 & 0.0957 & $0.437 *$ \\
\hline $\begin{array}{c}\text { Customer service } \\
\text { awareness }\end{array}$ & 0.78 & 0.0892 & 0.61 & 0.0945 & $1.332 *$ \\
\hline Self-independent Ability & 0.56 & 0.0622 & 0.48 & 0.0002 & 0.566 \\
\hline Bargaining Power & 0.16 & 0.0869 & 0.17 & 0.0924 & $0.935^{*}$ \\
\hline Strategic Planning & 0.13 & 0.0967 & 0.20 & 0.0017 & 0.943 \\
\hline Diligence & 0.20 & 0.0898 & 0.25 & 0.0017 & 0.977 \\
\hline Outlook ability & 0.52 & 0.0726 & 0.53 & 0.0091 & 0.853 \\
\hline
\end{tabular}

After the above difference test, it can be found that there are 20 competency characteristics which have
obvious difference among sales staff who are in varied levels performance. Then the paper proceeds clustering analysis for the above 20 competencies through SPSS 20.0 and the result is as follows: 


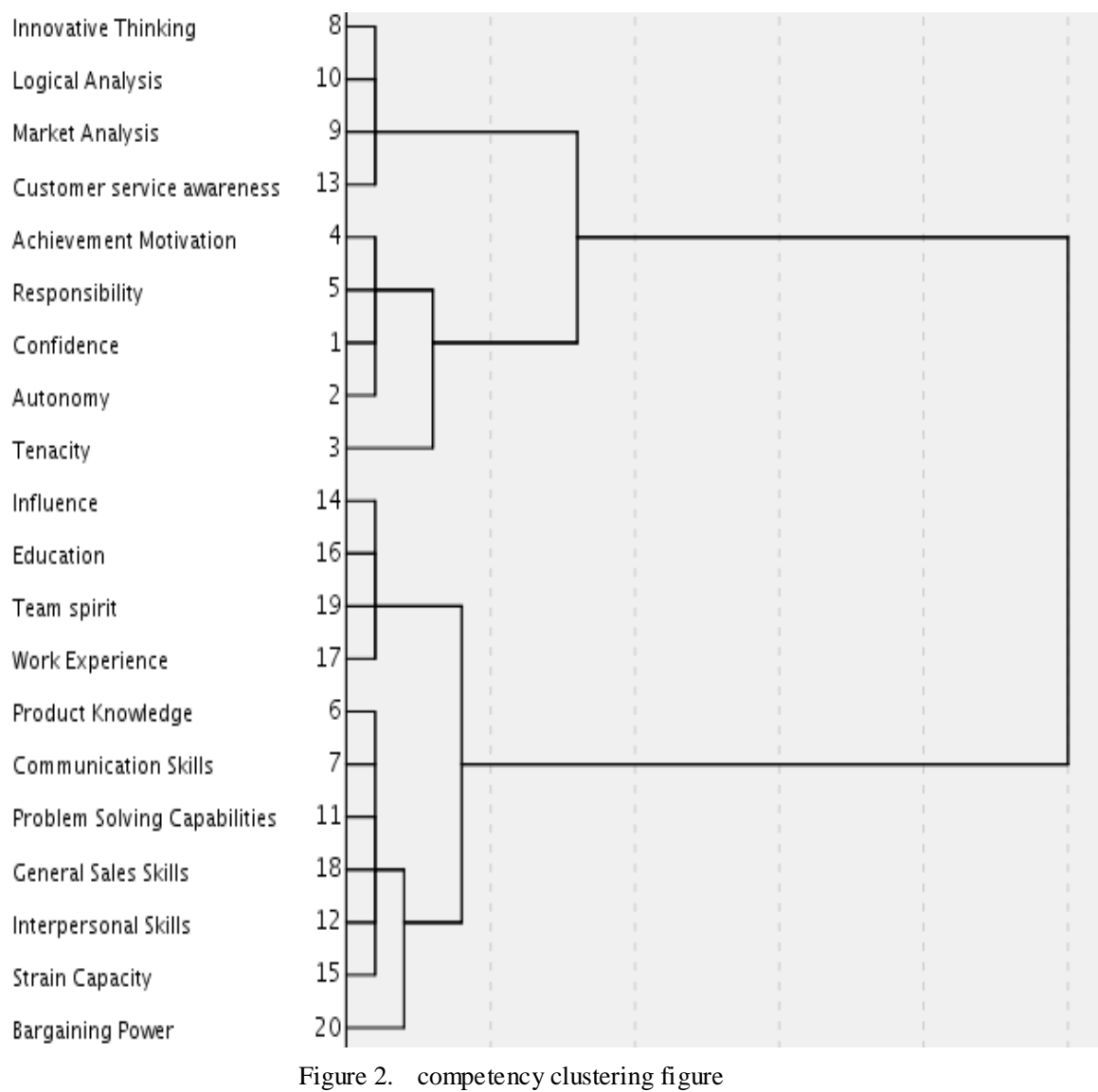

Through sorting behavioral event interview recording, utilizing SPSS to calculate analysis and T-test, and based on the cluster analysis tree diagram, the paper finally constructs four dimensions, such as basic characteristics group, psychological quality group, logic thinking group, business abilities group and 20 quality items to summarize and describe Huansu sales staff's competency index system.

The first class is basic characteristics group, includes education, work experience, influence and team spirit.

The second class is psychological quality group, includes confidence, autonomy, tenacity, responsibility, achievement motivation.

The third class is logic thinking group, includes logical analysis, market analysis, innovative thinking, customer service awareness.

The fourth class is business abilities group, including product knowledge, general sales skills, problem solving capabilities, interpersonal skills, strain capacity, Communication Skills, Bargaining Power.

\section{VERIFY THE INDEX SYSTEM}

The paper further verifies the index system in assurance to its science and rationality. According to the four dimensions and 20 quality items, the paper designs the corresponding research questionnaire. The questionnaire asks respondents mark according to perceived importance of using 5 Likert scale. ( 5 is extraordinary important, 4 is very important, 3 is important, 2 is general important 2, 1 is indifferent ). As shown in Table IV:

TABLE IV. PART OF THE QUESTIONNAIRE FOR THE INDEX S YSTEM VERIFYING

\begin{tabular}{|c|c|c|c|c|c|}
\hline \multirow{2}{*}{$\begin{array}{l}\text { Questions } \\
\text { full of confidence for sales work and their ability }\end{array}$} & \multicolumn{5}{|c|}{ Importance degree } \\
\hline & 5 & 4 & 3 & 2 & 1 \\
\hline treat every customer and complete each task earnestly & 5 & 4 & 3 & 2 & 1 \\
\hline willing to concentrate on work and improve sales performance & 5 & 4 & 3 & 2 & 1 \\
\hline Love the sales team and willing to share with others & 5 & 4 & 3 & 2 & 1 \\
\hline ........ & 5 & 4 & 3 & 2 & 1 \\
\hline
\end{tabular}


On the sample selection, the paper anew selects high performance group and general performance group from Sichuan province's 16 primary dealers. It issues total 100 questionnaires and withdraws 89 questionnaires, so the recovery rate is $89 \%$. After a detailed and comprehensive selection, there are altogether effective questionnaire out of 82 questionnaires and the effective rate is $92.1 \%$. The paper uses SPSS20.0 software to verify the investigation data, the results of the analysis are as shown in Table V:

TABLE V. SAMPLE ANALYSIS RESULTS

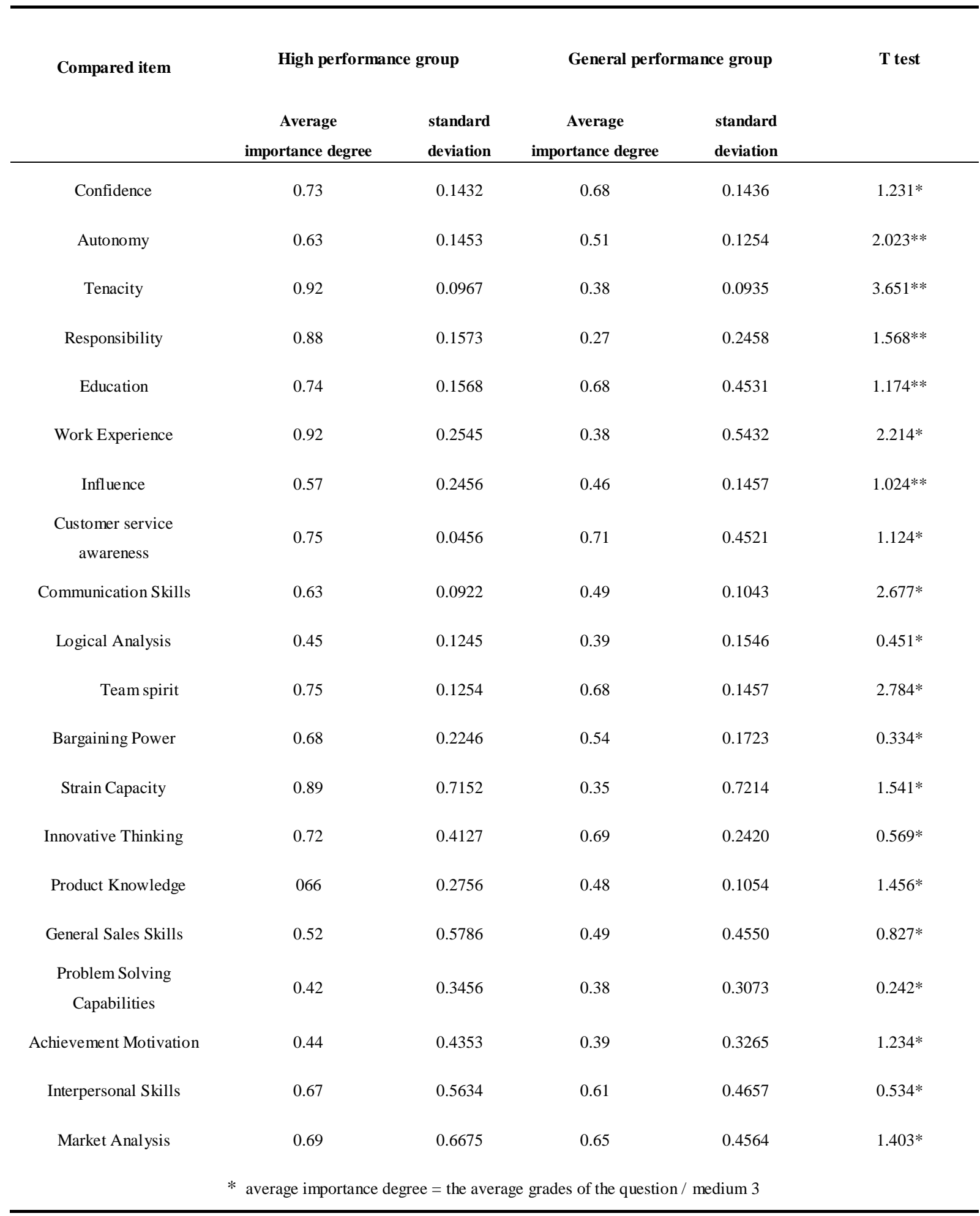

Learning from the data in Table 4-2, it can be concluded that all the competency characteristics items of Huansu sales competency index system has favorable difference, the competency index system has good stability and representative. Compared the data between high 
performance group and general performance group, the result is shown in Fig.3:

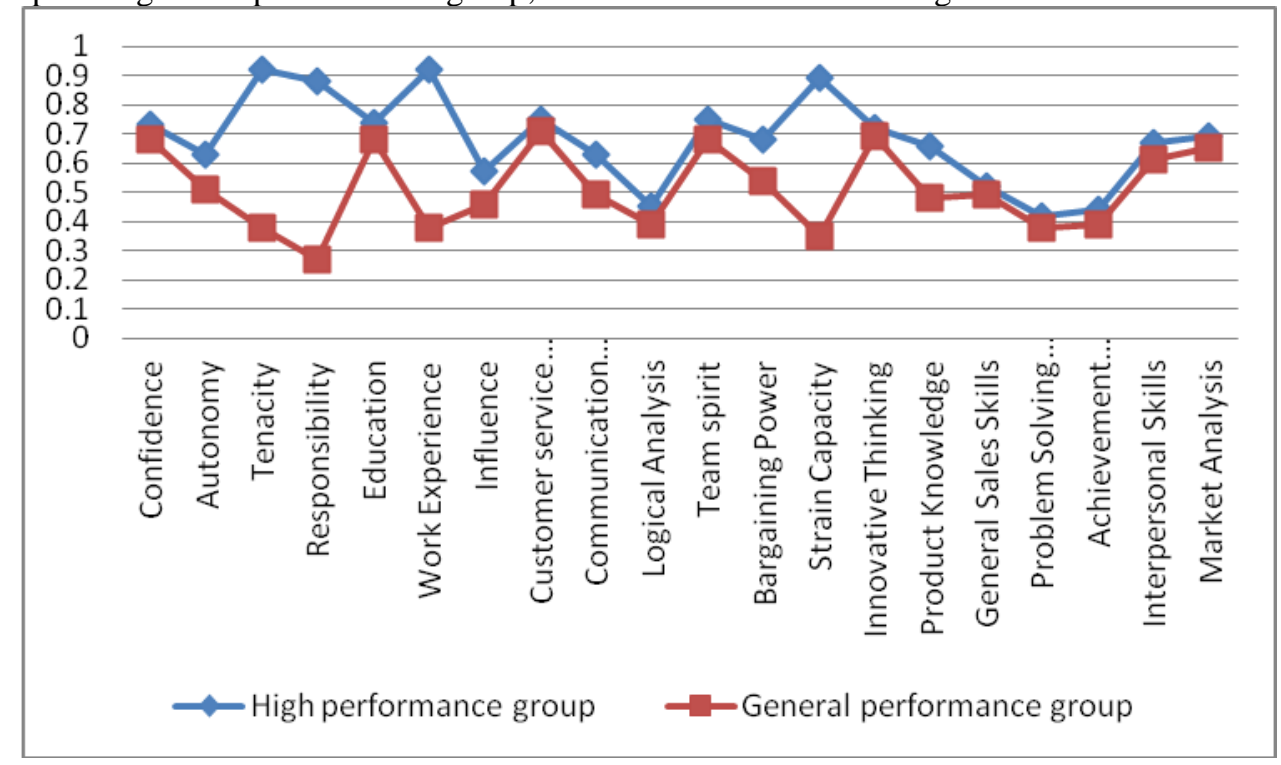

Figure 3. Contrast of high performance group and general performance group

It can be seen from Fig.3 that the majority of competency quality items are nearly uniformly between two groups, which also further proves the index system has preferable representativeness and universality. But it also can be observed from Fig.4-1 there are difference in tenacity, responsibilities, working experience, strain capacity between two groups of employees, which manifests two groups of employees has obvious cognitive differences on these four contents, which is also in accordance with the actual situation.

\section{CONCLUSION AND FURTHER ANALYSIS}

Based on previous study, the paper builds Huansu auto sales personnel competency evaluation index system in Sichuan area. The system is composed of four groups and 20 index and card comprehensively current competence quality of sales staff. The paper provides reference value for Huansu auto enterprise to select outstanding sales staff and predict their performance Meanwhile, the paper also has some inadequacies: Firstly, the result will be affected by the interviewer and the interviewee's subjective ideas because the details of using behavior event interview (BEI) technology are not easy to master quickly; Secondly, the interview results cannot cover all entirely sales personnel competent characteristics. to a certain extent due to the limitation of research conditions that the interview personnel are only the representative sales staff in Sichuan province.

\section{ACKNOWLEDGMENT}

I am grateful to my professor $\mathrm{Li}$-hong Han for teaching me research attitude and giving careful guidance and modification to the paper. Thanks Huansu Auto for providing me an opportunity to do empirical research, which ensures research data reliable and authentic!

\section{REFERENCES}

[1] McClelland D C. Testing for competence rather than for intelligence[J]. American Psychologist, 1973, (28): 1-14

[2] Clarke, Mary. Appraisals assess staff competence[J]. Railway Gazette International, 2011, 167(2): 54

[3] Brian Lambert, RichardE. Plank. A Competency Model for Entry Level Business-to-Business Services Salespeople[J]. Service Marketing Quarterly, 2014, 35(1): 84-103

[4] Brian D. Johnson, Laurie D. Berdahl. A Parenting Competency Model[J]. Parenting, 2014, 14(2): 92-120

[5] Donna Rodriguez, Rita Patel. Developing competency models to promote integrated human resource practices[J]. Human Resource Management, 2002, 41 (3)

[6] Sisakhti, Reza. ATD reveals NEW WORLD-CLASS sales competency model[J]. Talent Development, 2015, 69 (5): 52-57

[7] Nornazira Suhairom, Aede Hatib Musta'amal. The Development of Competency Model and Instrument for Competency Measurement: The Research Methods[J]. Procedia - Social and Behavioral Sciences, 2014, 152

[8] Boyatzis. The Theory of Buyer Behavior[M]. New York: Wiley, 1982

[9] Maureen C McMahon, Glenn R Stryjewski MPH. Pediatrics A Competency-Based Companion[M]. Amsterdam: Elsevier, 2011

[10] CFP Board. The Financial Planning Competency Handbook[M]. New York: Wiley, 2013 